\title{
The Transportation of the Djehutihotep Statue Revisited
}

\author{
Simon Ayrinhac \\ Institut de Minéralogie, de Physique des Matériaux et de Cosmochimie (IMPMC) Sorbonne Universités - UPMC \\ Université Pierre et Marie Curie Paris 6, CNRS UMR 7590 Muséum National d'Histoire Naturelle, IRD UMR 206 BC \\ 115, 4 place Jussieu, 75252 PARIS Cedex 05 France \\ Corresponding author: simon.ayrinhac@impmc.upmc.fr
}

( Manuscript received 01 December 2015; accepted 03 April 2016; published 15 June 2016 )

\begin{abstract}
The transportation of a colossus painted in the ancient Egyptian tomb of Djehutihotep (Dayr al-Barshā) is known as an example of lubrication application. However the benefits and the nature of lubrication used by ancient Egyptians are controversial. In order to clarify this issue, the physical parameters involved in the transportation are carefully reviewed. The traction force is a key parameter, and is evaluated by simple physical models and the results of biomechanical and ergonomic studies. The results of this work suggest high traction force can be produced only with an excellent team coordination, and the friction coefficient between sledge and ground is efficiently reduced by hypothetical methods which exclude probably wood-on-wood or wood-on-sand surface contacts.
\end{abstract}

Keywords: history of tribology, biomechanics, friction, lubrication, archaeology, tug-of-war

\section{Introduction}

The Egyptian tomb of the nomarch Djehutihotep has a wall that depicts the hauling of a colossal statue [1,2]. This tomb, located at Dayr al-Barshā and dated around 1880 B. C., was first referred by J. M. Wansleben's diaries in the seventeenth century [3]. The archaeologist Percy E. Newberry undertook a complete survey of the tomb in November-December 1891 and later published a complete description of the tomb [1].

At the time men were, around the world and throughout the ages, the primordial source of energy to transport huge loads. For example, megaliths was erected during the Neolithic age [4] and triremes were hauled on the beach by large teams in Antiquity [5]. The use of the brutal physical force decreased with the development of techniques and scientific knowledge. In this way, blocks of 100 tonnes were hauled in China [6] by only 50 men using tribology principles.

This kind of knowledge was possessed by the Egyptians, as demonstrated by the Djehutihotep tomb scene. In a seminal calculation, Dowson showed in his book History of tribology [2] that the coefficient of friction between the sledge of the statue and the ground is compatible with lubricated wood-on-wood surfaces, and the man pouring water appears as the first known tribologist in history. The use of lubrication is confirmed by other Egyptian paintings, such as the transporting of the statue of Ti [2]. However, a recent article by Fall et al.
[7] challenges this interpretation and argues that it is possible to drag the sledge over sand, because they found that the coefficient of friction between wood and sand decreases significantly if a small amount of water is added to sand. More generally, the role of lubrication is important in evaluating the Egyptian workforce and in understanding the techniques involved in the building of the pyramids, which remain conjectural [8-10].

Basically the traction force $F_{T}$ required to move the sledge carrying the statue at a constant speed may be $[2$, 11]:

$$
F_{T}=\mu_{K} M g
$$

where $\mu_{K}$ is the kinetic coefficient of friction, $M$ is the mass of the statue with its sledge and $g$ is the gravitational acceleration at Earth's surface. When the sledge is stopped, the static coefficient of friction $\mu_{S}$ may be considered instead of the kinetic coefficient, with generally $\mu_{S}>\mu_{K}$. The coefficient of friction is a key parameter in the transportation of the colossus; it depends on the nature of the contact surfaces and possible lubrication $[2,7,12]$.

The traction force provided by the haulers must be equal to or greater than $F_{T}$. We will evaluate this key parameter using a theoretical approach supported by biomechanical and ergonomic experimental studies. Two ways to produce traction force are investigated: a steady force (section 2.1) that depends strongly on the friction between feet and ground (section 2.3), and a high transient force exerted in a very short time (section 2.4). 
The issues of the hauling technique (section 2.2) and teamwork efficiency (section 2.5) are discussed. Finally, the friction obtained by the calculation is compared to tabulated and experimental values (section 2.6). All the physical parameters needed are carefully reviewed and evaluated in the Appendix.

\section{Methods and results}

\subsection{Steady traction force}

During pushing (or pulling), the balance of forces (see Fig. 1) involves $F_{T}=F_{\|}, \quad m g=F_{\perp} \quad$ with $\mu=F_{\|} / F_{\perp}$, so the maximum traction force is limited by the static coefficient of friction between feet and ground $\mu$. The traction force provided by $N$ workers to their maximum capability is

$$
F_{T, \max }=\mu N m g \text {. }
$$

If $F_{T, \max }$ is reached, the team slips, and the movement of the sledge is stopped. This equation emphasises the influence of the weight $m g$ and the coefficient of friction $\mu$ on the traction $F_{T}$. However, this simple model does not account for the complexity of the human body. The magnitude of the traction force given by Eq. (2) may be compared to the results of experimental studies.

The results of several studies are presented in Table 1. Kroemer [13] reported a minimum pushing force of $500 \mathrm{~N}$ if the feet are anchored on a perfectly nonslip ground. It was shown that this minimum force decreases when $\mu$ decreases. The average body weight of the subjects was not recorded in this study because Kroemer considered that weight is not a practical predictor of force capability. For $\mu$ close to unity and an unconstrained posture, Pheasant [14] showed that the pulling force can reach the value of the weight when the handle height is $62.5 \mathrm{~cm}$ (the optimal value is still

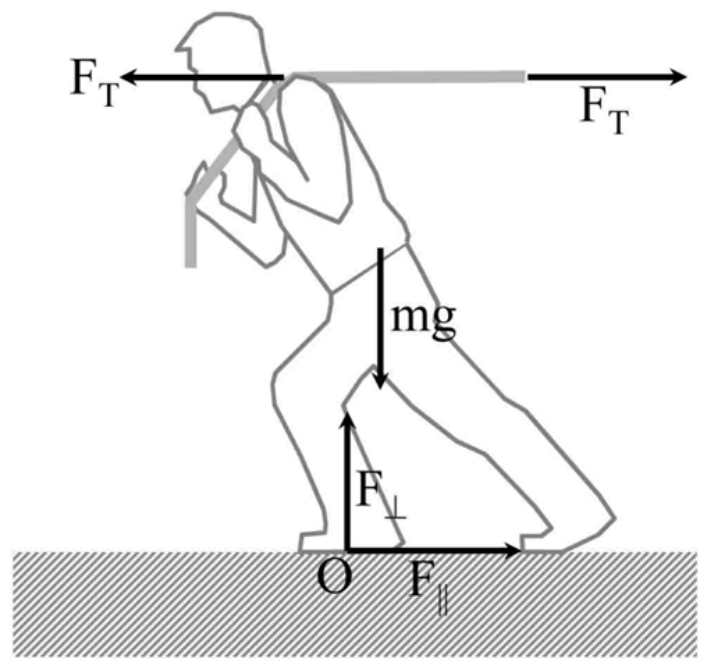

Fig. 1 Balance of forces during pushing: $F_{T}$ is the pushing force, $m g$ is the body weight applied to the centre of mass, $F_{\|}$and $F_{\perp}$ are respectively the tangential and normal ground reaction forces controversial, see ref. [15]). Chaffin [16] noticed that, during a pushing task, the force increases if one foot is in front of the other and if two hands are used. Tiwari et al. [17] studied a large population of male Indian agricultural workers and found a $250 \mathrm{~N}$ pushing force. Their average weight and height are not far from the anthropometric data of Egyptian workers in the Middle Kingdom (see the Appendix). The experiments are carried out with barefoot on a flat surface, but the friction coefficient is not specified. Chen et al. [18] measured the pushing force exerted by young Taiwanese people to be 290 N. According to the authors, this weak pull force is due to a low friction level of $\mu=0.48$, which represents the floor of Taiwanese hypermarkets. All these results confirm the pertinence of Eq. (2) despite its simplicity, and can be applied to Egyptian workers.

\subsection{Push or pull?}

Pushing and pulling are two different ways to exert a traction force, which imply specific body postures for haulers, and specific techniques for the teamwork. This difference in techniques can be illustrated by two cases. In an experiment carried out by Lehner replicating in real-size the hauling of pyramid blocks [10], the haulers were in a tug-of-war configuration, and pull. On the contrary, Assyrian workers were harnessed by the chest-like draft animals during the transportation of a colossal bull [2] and can be considered to have been pushing.

In the case of the Djehutihotep scene, the haulers are depicted with their bodies turned in the same direction to the statue, which suggests that they push rather than pull, if it is not an artistic convention. The men standing at the free end of the ropes wear the rope on their shoulders and suggest a possible posture adopted by all the team to exert the traction force.

This issue could be a problem, but it appears that the magnitudes of the pull and push forces are roughly equal (see Table 1). So, only considering the force magnitude, there is no need to know the exact technique to haul the statue.

\subsection{Friction between feet and ground}

Ergonomic studies show that the ability to pull is related to the friction coefficient between feet and ground. The coefficient of friction between barefoot skin and ground has to be evaluated, the nature of the ground spanning from paved road to desert sand.

The friction of bare feet on indoor surfaces has been extensively studied due to the public health problem posed by the risk of falls and injuries (e. g. [19]). Although skin friction has been investigated [20], it is difficult to use directly the measured friction coefficients, because friction depends on many parameters such as skin humidity, loading or the grain size of the floor. The minimum value to ensure safe walking is $\mu=0.3$. The most relevant data are given by Nigg et al. [21] for friction between shoes and different grounds in the context of sports, giving $\mu=0.4-1$ for shoes on hard and 
Table 1 Results of ergonomics and biomechanical studies for $n$ male subjects, in various conditions

\begin{tabular}{lccccccc}
\hline \multicolumn{1}{c}{ Study } & Location & $n$ & $\begin{array}{c}\text { av. mass } \\
(\mathrm{kg})\end{array}$ & $\begin{array}{c}\text { av. height } \\
(\mathrm{cm})\end{array}$ & $\begin{array}{c}\text { push force } \\
(\mathrm{N})\end{array}$ & $\begin{array}{c}\text { pull force } \\
(\mathrm{N})\end{array}$ & $\mu$ \\
\hline Kroemer (1974) [13] & Fig. 9 & 73 & - & - & $290 \pm 60$ & - & $\simeq 0.6$ \\
Pheasant (1982) [14] & Fig. 6 & 10 & $69.8 \pm 9.1$ & $175.0 \pm 7.6$ & $\simeq 700$ & $\simeq 700$ & $\simeq 1$ \\
Chaffin (1983) [16] & Table 4 & 3 & $75 \pm 10$ & $180 \pm 9$ & $342 \pm 101$ & $270 \pm 100$ & $>0.8$ \\
Tiwari et al (2010) [17] & Table 2 & 604 & $51.4 \pm 6.5$ & $164.6 \pm 5.9$ & $254.1 \pm 53.0$ & $234.5 \pm 43$ & - \\
Chen et al (2011) [18] & Fig. 2 & 30 & $70.3 \pm 15.1$ & $173.3 \pm 5.6$ & $\simeq 290$ & $\simeq 270$ & 0.48 \\
\hline
\end{tabular}

loose grounds.

On a loose ground (such as sandy ground), the soil flows easily and produces bumps ahead the feet, which increase the anchor in the ground; therefore, the friction coefficient increases. In this case, if the feet plough the ground, the friction coefficient is used as an approximation because the friction coefficient as defined above does not apply [11]. To deduce a realistic value of $\mu$ on a loose ground the situation of people pushing a car in the desert can be considered. An average handle height is estimated to be $110-130 \mathrm{~cm}$, which corresponds to $\mu \approx 1$ (see Table II in [13]).

Thus an Egyptian worker can provide a steady traction force ranging from 250-500 $\mathrm{N}$ depending the nature of the ground, but it is possible to reach higher values, as confirmed by tug-of-war studies.

\subsection{Transient traction force}

The human body is able to produce very high output forces in a short time, typically over $0.5 \mathrm{~s}$ [22]. In a tug-of-war, to exert the maximum traction force during dynamic pulling, the puller anchors his feet on ground and moves the trunk backward [23]. The puller uses both legs and arms, and can increase the normal force applied to the ground. This can be demonstrated by a vertical jump over a force platform laid on the ground [24]. Before the jump, during the preliminary downward movement, the ground reaction force $F_{\perp}$ easily reaches twice the body weight force (see Fig. 2(a) in [24]). An increase of $F_{\perp}$ leads to an increase of $F_{\|}$through the constant coefficient $\mu=F_{\|} / F_{\perp}$ and the pulling force $F_{T}$ can exceed twice the body weight if $\mu \approx 1$.

In addition, the rope plays a significant role and helps the pullers. In the case of tug-of-war, a large backward movement (analogous to a short run-up, or a climber's fall [25]) helps the puller to exert a high transient force due to the inertia of the body. If the rope has sufficient elasticity, the energy provided by the pullers is stored in the rope. Egyptians ropes were made with natural fibers, such as date palm fibers [26], but their exact viscoelastic properties are unknown.

The pulling force is, for a team,

$F_{T, \max } \geq 2 N m g$.

This can be compared to experimental results obtained in tug-of-war sport studies [27,28]. In an

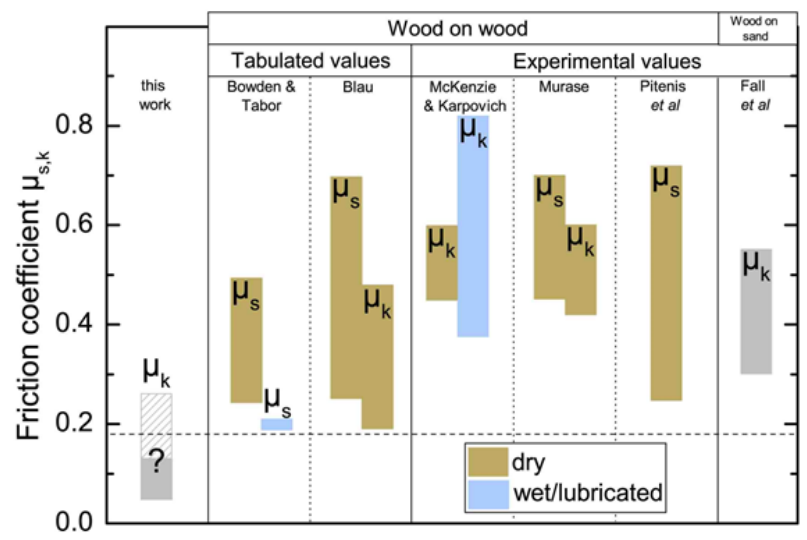

Fig. 2 Friction coefficients (static or kinetic) from different sources: on the left the range of values given by Eq. (4) compared to the values of Bowden and Tabor [31], Blau [10], McKenzie and Karpovich [32], Murase [33], Pitenis et al. [36] and Fall et al. [6]. According to the present work, the dashed region is accessible only with high traction forces and an efficient teamwork. The question mark (?) indicates the range which remains hypothetical due to lack of data in the literature. It reflects also the lack of knowledge on the real conditions of the transportation

experimental study done with female elite high school athletes on a non-slipping ground, the force was recorded as a function of time [27]. The maximum force for a female athlete with an average mass of $59.1 \mathrm{~kg}$ was measured to be $1500 \mathrm{~N}$ during a short time of around $0.2 \mathrm{~s}$, which exceeds $2 \mathrm{mg}$ in agreement with Eq. (3).

This traction force represents an upper limit for a team, considering a perfect teamwork efficiency. If the pullers are not all synchronous, the total force is reduced.

\subsection{Teamwork efficiency}

The total force generated by a team is expected to be equal to the sum of individual forces. However, if the size of the team increases, the measured total force is lower than the expected total force. The reduction of teamwork efficiency compared to single work is known as the Ringelmann effect [29-31]. Ringelmann explained this effect by a coordination loss, but currently it is 
considered also as a motivation loss [32]. Here, this effect cannot be ignored due to the number of workers involved, especially because the initial results obtained by Ringelmann concerned the ability to pull a rope.

In the case of the exertion of high traction forces, coordination between pullers is crucial. The high force peaks should be simultaneous to avoid a loss of force, as confirmed by experimental results obtained on pairs of pullers [28], which emphasises the importance of timing skill among members of the team.

For these reasons, the human performances implied by Eqs. $(2,3)$ are probably overestimated. However the lack of coordination can be reduced by management techniques. In the case of statue transportation, the coordination could be achieved by the rhythm given by the man who stands on the statue loincloth.

\section{Discussion}

Finally, combining Eqs. (1-3), we obtain the following relation

$$
\mu_{K} \leq \alpha \frac{N m}{M} \text { where } \alpha \approx\left\{\begin{array}{c}
0.4 \leq \mu \leq 1 \\
2
\end{array}\right.
$$

The paramaters $N, m$ and $M$ are carefully evaluated in the Appendix thus $N m / M=0.13 \pm 0.02$, so finally $0.05 \leq$ $\mu_{K} \leq 0.26$. This range of values includes that determined by Dowson [2] $\left(\mu_{K}=0.23\right)$. Bowden and Tabor [33] give $\mu_{\mathrm{S}}=0.2$ for wood-on-wood lubricated static friction, so Dowson concluded that the statue is carried over wood beams spread out on the ground. However, as shown by Blau [11], a wide range of tabulated values exists for wood-on-wood friction. These tabulated values are aggregated and they are shown in Fig. 2. As underlined by Blau, these values are far from applied problems and should be used carefully. Experimental data about wood-on-wood friction are scarce (e. g. [34-38]) and cover a wide variety of woods including balsa, cork or plywood. The experimental values shed doubt on the low value given by Bowden and Tabor of $\mu_{S}=0.2$, which is only a typical value of friction. This value is given without any literature reference, does not possess a large range expected for realistic situations and seems quite arbitrary.
Figure 2 compares the friction coefficient determined by Eq. (4) and the experimental wood on wood friction coefficients. McKenzie [34] observed that the kinetic friction coefficient for wet wood decreases when the sliding speed increases. Pitenis et al. [38] found the friction coefficient is reduced by a specific surface preparation: sliding directions aligned with the grain, inclusion of wood dust, etc. Probably, the Egyptians had empirical methods to reduce the friction, but currently they remain hypothetical.

Additionally, wood-on-sand friction may be considered. Fall et al. [7] conducted a laboratory experiment with a small object sliding in a sandbox. They show that adding water in sand decreases the coefficient of friction between sand and wood to $\mu_{K}=0.3$. Physical parameters between the laboratory experiment and the real-size conditions are compared in Table 2 and appear quite different. Although the sliding speed is similar between the laboratory experiment and the real-size conditions, the contact pressures are separated by two orders of magnitude. The high contact pressure underlined in Table 2 raises a question about the friction coefficient at such high pressure. As experimentally shown by Konečný in the case of a wood-on-wood contact [39], the friction coefficient decreases with an increase of the normal force and the huge weight of the statue appears as a favourable setting for friction. However, the value $\mu_{K}=0.3$ is much higher than the maximum value attainable by the pullers. Furthermore, the road between the Hatnub quarry and the Nile is well known in archeology [40] and there is no reason to transport the statue through the desert. For these reasons, a scenario with hauling directly on sand seems unlikely.

The inherent limitations of Eq. (4) leave the door open to various hypotheses. Since $\mu_{K}$ is found below the minimum tabulated values for watered wood-on-wood friction coefficient, a lubricant other than water can have been used. The use of oil as lubricant in ancient Egypt is hypothetical [12] and do not correspond to the tomb inscriptions which read "carrying water (by men) of the house of eternity" [1]. The use of mud as a lubricant is possible, following the field experiments of Chevrier done in $1920 \mathrm{~s}[8,43]$. Another trivial possibility is that

Table 2 Comparison between the laboratory experiment of Fall et al [6] and the evaluation of real-size physical values (see the Appendix). †This sand have a similar polydispersity than a sand found in the Egyptian desert

\begin{tabular}{ccc}
\hline & laboratory & real-size \\
\hline material of the sledge & sandpaper glued on PVC & hard wood \\
type of surface & sand (from Nemours or Iran) $\dagger$ & artificial road (not sandy) \\
contact surface & $11 \times 7.5 \mathrm{~cm}^{2}$ & $5 \mathrm{~m}^{2}$ \\
loading & up to $20 \mathrm{~N}$ & $715 \mathrm{kN}$ \\
contact pressure & $2 \mathrm{kPa}$ & $140 \mathrm{kPa}$ \\
sliding speed $v$ & $0.01 \mathrm{~m} / \mathrm{s}<v<0.8 \mathrm{~m} / \mathrm{s}$ & $0.14 \mathrm{~m} / \mathrm{s}<v<0.34 \mathrm{~m} / \mathrm{s}$ \\
\hline
\end{tabular}


the picture does not represent a reliable number of pulling people $[12,41]$. Such as field experiments conducted with the giant statues of the Easter Island (walking moai) [42], further experiments in real conditions are needed to understand the Egyptian techniques, since there is some evidence that carrying such a huge statue was effectively performed by the ancient Egyptians [43,44].

\section{Conclusions}

In summary, we investigated all the parameters of the seminal calculation proposed by Dowson on the hauling of the Djehutihotep statue. Based on biomechanics and ergonomic studies, two hauling methods are investigated. The first method is based on a steady traction force. Introducing the static coefficient of friction between feet and ground $\mu$, the traction force of an Egyptian worker ranges between 250-500 $\mathrm{N}$, depending on $\mu$. Experimental studies state that there is no significant difference between push and pull, which avoids discussing the details of the hauling technique. The second method is based on a dynamic exertion of high pulling force, which supposes a very strong coordination between pullers. Each method implies a likely range of values of the kinetic friction coefficient $\mu_{K}$ between the sledge and the ground. Comparison with experimental values suggests an efficient reduction of friction during transportation, by lubrication or a specific treatment of surfaces in contact. This kind of calculation is limited by the evaluations of friction coefficients and the performances of human workers, so careful investigations in real conditions are needed.

\section{Acknowledgements}

The author is indebted to M. Gauthier for fruitful discussions about physics in general, and particularly about tug-of-wars. The author is also pleased by the close reading of $\mathrm{H}$. Willems and his helpful comments.

\section{Appendix}

To provide a good insight of the statue transportation, an accurate evaluation of involved physical parameters is required. The relevant literature data are collected in
Table 3.

The number of people involved in the hauling is 172 , as counted in the drawing of the wall tomb by Newberry [1]. Since its discovery, the original picture suffered alteration or erosion, and currently several parts are missing. However, in many books or articles, the picture is redrawn and missing parts are invented (in [12] for example), or the picture is unnecessary truncated (e. g. in [7]).

Information on the stature and body mass of Egyptian people was compiled by Raxter [45] through the history of Egypt. The height and the mass of an Egyptian male in Middle Kingdom are respectively around $1.60 \mathrm{~m}$ and $55 \mathrm{~kg}$. As explained in the body of the article, the body mass can be used to evaluate the Egyptian workforce.

The weight of the statue is a crucial parameter to understand its transportation. According to the hieroglyphic inscriptions on the tomb wall [1], the height of the statue was 13 cubits $(H=6.825 \mathrm{~m})$. The height of the statue (although the upper part of the head is missing) can be scaled from the known size $h$ of the man pouring water with $H=4.23 h$, which gives $H=6.9 \mathrm{~m}$ and confirms the inscriptions. Considering that the picture on the tomb wall does not accurately reflect the exact proportions of the statue, the volume of the statue is evaluated using the canonical proportions of similar seated statues (see Table 4). Assuming a simple homothetic relation between statues, the average scaling factor is $V / H^{3}=0.082 \pm 0.006$. In this value, the uncertainty accounts for the statistical dispersion and error on the volume determination for each statue. Finally, the volume is $V=25.9 \pm 1.9 \mathrm{~m}^{3}$.

The Djehutihotep statue came from the quarry of Hatnub [40], an isolated place around $18 \mathrm{~km}$ south-west of the actual town of El-Armana [46]. The statue was carved from a white stone called Egyptian alabaster, but the terminology is controversial and other terms are employed: calcitic flowstone [47], calcite alabaster [48], or also travertine [49]. However, terminology is important because various names cover different kinds of alabaster with densities ranging from $2300-2700 \mathrm{~kg} / \mathrm{m}^{3}$. Using the calcitic flowstone density [47], the mass of the statue (without the sledge) is $70 \pm 5 \mathrm{t}$. This value is higher than Newberry's, who estimated the mass of the statue at $58 \mathrm{t}[1]$.

Table 3 Relevant data for the transportation of the Djehutihotep statue. The acronym MK refers to the Middle Kingdom period (2106-1786 B. C.) [53] in the history of ancient Egypt

\begin{tabular}{ccc}
\hline Parameter & value & Ref. \\
\hline one Egyptian royal cubit during MK & $52.5 \mathrm{~cm}$ & {$[55]$} \\
number of haulers & $N=172$ & {$[1]$} \\
Egyptian male average height during MK & $h=163.3 \pm 4.9 \mathrm{~cm}$ & Table 10 in [45] \\
Egyptian male average mass during MK & $m=55.6 \pm 6.7 \mathrm{~kg}$ & Table 17 in [45] \\
average useful power supplied by man & $P_{a v}=75 \mathrm{~W}$ & {$[51]$} \\
Egyptian alabaster bulk density & $\simeq 2.7 \mathrm{~g} / \mathrm{cm}^{3}$ & {$[47]$} \\
\hline
\end{tabular}


Table 4 Dimensions of various Egyptian seated statues. Volume is calculated through the weight with density of the material (porphyritic diorite $\rho=2.8 \mathrm{~g} / \mathrm{cm}^{3}$, granodiorite $\rho=2.6 \mathrm{~g} / \mathrm{cm}^{3}$ ) [54]. The acronyms MMA and MFA stand for respectively Metropolitan Museum of Art (New York) and Museum of Fine Arts (Boston)

\begin{tabular}{ccccccc}
\hline Statue & Location & $\begin{array}{c}\text { Accession } \\
\text { Number }\end{array}$ & Material & $\begin{array}{c}\text { Mass } M \\
(\mathrm{~kg})\end{array}$ & $\begin{array}{c}\text { Height } H \\
(\mathrm{~m})\end{array}$ & $\begin{array}{c}\text { Volume } V \\
\left(\mathrm{~m}^{3}\right)\end{array}$ \\
\hline Amenhotep III & MMA & 22.5 .2 & porphyritic diorite & 2766.9 & 2.28 & $0.99 \pm 0.04$ \\
Amenhotep III & MMA & 22.5 .1 & porphyritic diorite & 3674.1 & 2.541 & $1.31 \pm 0.05$ \\
Lady Sennuwy & MFA & 14.720 & granodiorite & 1079.56 & 1.702 & $0.42 \pm 0.02$ \\
Anonymous official & MFA & 14.723 & granodiorite & 56.2 & 0.65 & $(21.6 \pm 0.8) \times 10^{-3}$ \\
\hline
\end{tabular}

Furthermore we must take into consideration the weight of the sledge. A sledge model was designed by Engelbach in 1933 (see reproduction in [8]). The sledge is constituted by two lateral sliders and three transverse beams, which represent roughly a volume of $6 \mathrm{~m}^{3}$ and a contact surface with the ground of $5 \mathrm{~m}^{2}$. In the Nile valley, the scarcity of trees forced the ancient Egyptians to import wood from foreign regions: Syria, Nubia or Lebanon [50]. For example, Lebanon cedar (Cedrus Libani) was encountered in Egypt and was used for furniture, naval construction or buildings. The average density of cedar wood ranges from $450-580 \mathrm{~kg} / \mathrm{m}^{3}$.

Adding the weights of the sledge and the statue (the weight of the two men standing on the statue can be neglected), the total mass is $M=73 \pm 6 \mathrm{t}$, close to the value used by Dowson (60 t) [2], but half the value calculated by Barber (viz. 132 t) [41].

To maintain a constant traction force $F_{T}$ and a speed $v$, the power to supply is $P=F_{T} v$. The velocity of carrying the statue is given by:

$$
v=\frac{N P_{a v}}{F_{T}}
$$

where $P_{a v}$ is the useful power supplied by one man and the other parameters have been defined previously. The useful power supplied by a prime-age worker for long-term and constant work is estimated to be $P_{a v}=$ $75 \mathrm{~W}$ on a basis of $8 \mathrm{~h}$ /day for a $48 \mathrm{~h}$ week [51]. For power rate to be constant, the speed is inversely proportional to the pull and consequently to the weight of the sledge, as recorded for a walking team of sledge dogs [52]. The statue was transported from Hatnub quarry and was probably released on the right bank of the Nile, in a place called Tjerty [44]. The length of the road is around $15 \mathrm{~km}$ between Hatnub quarry and the Nile near the archaeological site of Kom el-Nana [46]. The average velocity calculated with Eqs. $(1,4,5)$ is $0.14-0.34 \mathrm{~m} / \mathrm{s}$ (i. e. one-fifth of normal walking speed), so the distance was covered in 2-5 days at $8 \mathrm{~h} /$ day, which is quite a low value considering the huge task accomplished.

\section{References}

[1] Newberry, P. E. and Fraser, G. W., "El Bersheh, Part 1: The Tomb of Tehuti-Hetep," Egypt Exploration Fund, 1893.
[2] Dowson, D., "History of Tribology," Bury ST Edmunds (UK), London, 1998.

[3] Sykora, T., "Wansleben en de Herontdekking Van Dayr Al-Barsha. Vansleb et la Redécouverte de Dayr Al-Barcha," In: De Meyer, M. and Cortebeeck, K. (eds.), "Djehoetihotep. 100 Jaar Opgravingen in Egypte. 100 ans de Fouilles en Egypte," Leuven, 2015, 39-43.

[4] Parry, R., "Megalith Mechanics," Proc. ICE-Civil Engineering, 138, 4, Thomas Telford, 2000, 183-192.

[5] Steinmayer, A. G. and Turfa, J. M., "Effects of Shipworm on the Performance of Ancient Mediterranean Warships," The International Journal of Nautical Archaeology, 25, 2, 1996, 104-121.

[6] Li, J., Chen, H. and Stone, H. A., "Ice Lubrication for Moving Heavy Stones to the Forbidden City in 15th- and 16th-Century China," Proc. National Academy of Sciences, 110, 50, 2013, 20023-20027.

[7] Fall, A., Weber, B., Pakpour, M., Lenoir, N., Shahidzadeh, N., Fiscina, J., Wagner, C. and Bonn, D., "Sliding Friction on Wet and Dry Sand," Physical Review Letters, 112, 17, 2014, 175502.

[8] Arnold, D., "Building in Egypt: Pharaonic Stone Masonry," Oxford University Press, New York, 1996.

[9] de Haan, H., "Building the Great Pyramid by Levering. A Mathematical Model," PalArch's Journal of Archaeology of Egypt, 6, 2, 2009, 1-22.

[10] Lehner, M., "The Complete Pyramids," Thames and Hudson, London, 1997.

[11] Blau, P. J. "The Significance and Use of the Friction Coefficient," Tribology International, 34, 9, 2001, 585-591.

[12] Nosonovsky, M., "Oil as a Lubricant in the Ancient Middle East," Tribology Online, 2, 2, 2007, 44-49.

[13] Kroemer, K. E., "Horizontal Push and Pull Forces Exertable when Standing in Working Positions on Various Surfaces," Applied Ergonomics, 5, 2, 1974, 94-102.

[14] Pheasant, S., Grieve, D., Rubin, T. and Thompson, S., "Vector Representations of Human Strength in Whole Body Exertion," Applied Ergonomics, 13, 2, 1982, 139-144. 
[15] Todd, A. I. "Current Trends in Research Focused on Pushing and Pulling," Ergonomics SA: Journal of the Ergonomics Society of South Africa, 17, 2, 2005, 42-53.

[16] Chaffin, D. B., Andres, R. O. and Garg, A., "Volitional Postures during Maximal Push/Pull Exertions in the Sagittal Plane," Human Factors: The Journal of the Human Factors and Ergonomics Society, 25, 5, 1983, 541-550.

[17] Tiwari, P., Gite, L., Majumder, J., Pharade, S. and Singh, V., "Push/Pull Strength of Agricultural Workers in Central India," International Journal of Industrial Ergonomics, 40, 1, 2010, 1-7.

[18] Chen, Y.-L., Lee, Y.-C. and Hsu, T.-C., "Isometric Push and Pull Strengths of Young Taiwanese Males," Industrial Health, 49, 6, 2011, 696-702.

[19] Ezzat, F., Hasouna, A. and Ali, W., "Friction Coefficient of Rough Indoor Flooring Materials," Engineering Sciences, 19, 2, 2008, 53-70.

[20] Derler, S., Huber, R., Feuz, H.-P. and Hadad, M., "Influence of Surface Microstructure on the Sliding Friction of Plantar Skin Against Hard Substrates," Wear, 267, 5-8, 2009, 1281-1288.

[21] Nigg, B., Denoth, J., Kerr, B., Luethi, S., Smith, D. and Stacoff, A., "Load Sport Shoes and Playing Surfaces," Sport Shoes and Playing Surfaces, 1984, $1-23$.

[22] Haff, G. G., Stone, M., O’Bryant, H. S., Harman, E., Dinan, C., Johnson, R. and Han, K.-H., "ForceTime Dependent Characteristics of Dynamic and Isometric Muscle Actions," The Journal of Strength \& Conditioning Research, 11, 4, 1997, 269-272.

[23] Ryuji, N., Nakagawa, M. and Yamamoto, H., "Backward Pulling Distance in Drop Phase for Japanese Elite Female Tug-of-War Athletes," Proc. ISBS - Conference Proceedings Archive, 1, 2007.

[24] Linthorne, N. P., "Analysis of Standing Vertical Jumps Using a Force Platform," American Journal of Physics, 69, 11, 2001, 1198-1204.

[25] Reali, G. and Stefanini, L., "An Important Question about Rock Climbing," European Journal of Physics, 17, 6, 1996, 348-352.

[26] Borojevic, K. and Mountain, R., "Microscopic Identification and Sourcing of Ancient Egyptian Plant Fibres Using Longitudinal Thin Sectioning," Archaeometry, 55, 1, 2013, 81-112.

[27] Tu, J.-H., Lee, C.-H. and Chiu, Y.-H., "The Analysis of Pulling Force Curves in Tug-of-War," Proc. ISBS-Conference Proceedings Archive, 1, 2005.

[28] Tanaka, K., Kawahara, S., Minamitani, N., Fukushima, M., Yulin, C. And Yamamoto, H., "Analysis of Timing Skill of Drop Exercise in Elite Indoor Tug of War Athletes," Proc. ISBS-Conference Proceedings Archive, 1, 2007.
[29] Ringelmann, M., "Research on the Animated Engines: Work of Man," Proc. Annales de 1'Institut National Agronomique, 12, 1913, 1-40.

[30] Kravitz, D. A. and Martin, B., "Ringelmann Rediscovered: The Original Article," Journal of Personnality and Social Psychology, 50, 5, 1986, 936-941.

[31] Liou, C., Won, T., Wang, J.-C. and Shin, J.-C., "The Study of Team Resultant Force Vanishing Percentage in Elite Tug-of-War Players," Proceedings of 23th International Symposium on Biomechanics in Sports (2005), Beijing, China, 399-402.

[32] Ingham, A. G., Levinger, G., Graves, J. and Peckham, V., "The Ringelmann Effect: Studies of Group Size and Group Performance," Journal of Experimental Social Psychology, 10, 4, 1974, 371-384.

[33] Bowden, F. P. and Tabor, D., "The Friction and Lubrication of Solids," Vol. 1, Clarendon Press, Oxford, 1950.

[34] McKenzie, W. and Karpovich, H., "The Frictional Behaviour of Wood," Wood Science and Technology, 2, 2, 1968, 139-152.

[35] Murase, Y., "Friction of Wood Sliding on Various Materials," Journal of the Faculty of Agriculture, Kyushu University, 28, 4, 1984, 147-160.

[36] Vaz, M. F. and Fortes, M., "Friction Properties of Cork", Journal of Materials Science, 33, 8, 1998, 2087-2093.

[37] Meng, Q., Hirai, T. and Koizumi, A., "Frictional Coefficients between Timber and Some Structural Sheet Materials," Journal of the Japan Wood Research Society, 54, 5, 2008, 281-288 (in Japanese).

[38] Pitenis, A., Dowson, D. and Gregory Sawyer, W., "Leonardo da Vinci's Friction Experiments: An Old Story Acknowledged and Repeated," Tribology Letters, 56, 3, 2014, 509-515.

[39] Konečný, V., "On the First Law of Friction," American Journal of Physics, 41, 4, 1973, 588-589.

[40] Shaw, I., "Hatnub: Quarrying Travertine in Ancient Egypt," Egypt Exploration Society, London, 2010.

[41] Barber, F. M., "The Mechanical Triumphs of the Ancient Egyptians," Kegan Paul, Trench, Trubner \& Co., London, 1900.

[42] Lipo, C. P., Hunt, T. L. and Haoa, S. R., "The Walking Megalithic Statues (Moai) of Easter Island," Journal of Archaeological Science, 40, 6, 2013, 2859-2866.

[43] Isler, M., "Sticks, Stones, and Shadows: Building the Egyptian Pyramids," University of Oklahoma Press, 2001.

[44] Willems, H., Peeters, C. and Verstraeten, G., "Where did Djehutihotep Erect His Colossal Statue ?," Zeitschrift für Ägyptische Sprache, 132, 2, 2005, 173-190. 
[45] Raxter, M. H., "Egyptian Body Size: a Regional and Worldwide Comparison," Ph. D. Thesis, University of South Florida, 2011.

[46] Harrel, J. and Storemyr, P., "Ancient Egyptian Quarries - an Illustrated Overview, 2009 - Quarry Scapes: Ancient Stone Quarry Landscapes in the Eastern Mediterranean," Geological Survey of Norway, Special Publication, 12, 2009, 7-50.

[47] Frumkin, A., Bar-Matthews, M., Davidovich, U., Langford, B., Porat, R., Ullman, M. and Zissu, B., "In-Situ Dating of Ancient Quarries and the Source of Flowstone (Calcite-Alabaster) Artifacts in the Southern Levant," Journal of Archaeological Science, 41, 2014, 749-758.

[48] Klemm, D. D. and Klemm, R., "The Building Stones of Ancient Egypt - a Gift of its Geology," Journal of African Earth Sciences, 33, 3-4, 2001, 631-642.

[49] Harrell, J., Broekmans, M. and Godfrey-Smith, D., "The Origin, Destruction and Restoration of Colour in Egyptian Travertine," Archaeometry, 49, 3, 2007,
421-436.

[50] Vercoutter, J. "Egypt and the Valley of the Nile. Tome I. From Origins to the End of the Old Empire. 12000-2000 B. C.," Presses Universitaires de France, Paris, 1994 (in French).

[51] Avallone, E. A., Baumeister, T. and Sadegh, A., "Marks Standard Handbook for Mechanical Engineers 11th Edition," McGraw-Hill, New York, 1996.

[52] Taylor, R. J. F., "The Work Output of Sledge Dogs," The Journal of Physiology, 137, 2, 1957, 210-217.

[53] Kitchen, K. A., "The Chronology of Ancient Egypt," World Archaeology, 23, 2, 1991, 201-208.

[54] Arnold, D., "The Monuments of Egypt: an A-Z Companion to Ancient Egyptian Architecture," IB Tauris \& Company, London, 2009.

[55] Pommerening, T. "Weights and Measures, Pharaonic Egypt," The Encyclopedia of Ancient History Vol. 12, Wiley-Blackwell, 2013, 7087-7092. 